Jurnal Kesehatan Perintis (Perintis's Health Journal) 7 (1) 2020: 32-40

Contents list available at JKP website

Jurnal Kesehatan Perintis (Perintis's Health Journal)

Journal homepage: https://jurnal.stikesperintis.ac.id/index.php/JKP

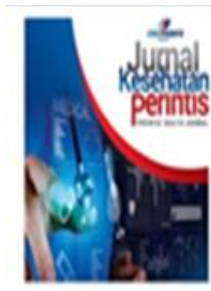

\title{
Korelasi Antara Body Mass Index (BMI) Dengan Blood Pressure (BP) Berdasarkan Ukuran Antropometri Pada Atlet
}

\author{
Luh Ari Arini* ${ }^{\star}$ I Ketut Wijana
}

Universitas Pendidikan Ganesha, Bali, Indonesia

\section{Article Information :}

Submission:Mar 11, 2020; Revised: Jun 30, 2020; Accepted:Jun 30,2020; Available online: Jul 12,2020

${ }^{*}$ Corresponding author : arikarini.91@gmail.com

\begin{abstract}
ABSTRAK
Agar dapat melakukan olahraga yang ditekuni dengan baik dan tanpa gangguan, seorang atlet harus dapat memperhatikan komposisi lemak dalam tubuh yang sesuai. Komposisi lemak dalam tubuh menunjukan derajat kesehatan seorang atlet, yang dapat dilihat melalui antropometri. Tujuan penelitian untuk mengetahui korelasional antara Body mass index/BMI dengan Blood pressure/BP berdasarkan ukuran antropometri atlet di Kabupaten Buleleng Tahun 2019. Metode penelitian menggunakan analitik observasional dengan desain cross-sectional. Populasi penelitian yaitu semua atlet Kabupaten Buleleng yang terpilih dan dipersiapkan komite olahraga nasional Indonesia/KONI mengikuti kejuaraan Nasional. Teknik pengambilan sampel accidental sampling, didapatkan atlet yang mengikuti tes sebanyak 121 orang. Metode pengumpulan data dengan pengukuran antropometri dan tekanan darah atlet. Analisis data menggunakan uji pearson corellation test pada taraf signifikansi $(\alpha<0,05)$ dengan menggunakan sistem komputerisasi. Hasil analisis data didapatkan nilai $p=0,466(\alpha=0,000)$, menunjukan adanya korelasi antara body mass index dengan blood pressure pada atlet. Sebagian besar atlet diketahui memiliki katagori BMl ideal dan BP yang normal. Setiap atlet harus tetap mengontrol massa tubuh dan tekanan darah, dengan selalu memperhatikan pola dan jadwal makan yang tepat, asupan nutrisi seimbang, latihan fisik yang teratur. Selain kesehatan fisik atlet juga harus menjaga kesehatan psikis, terutama menghindari rasa cemas yang berlebihan agar BMI dan BP tetap dalam kisaran katagori yang ideal, sehingga berdampak baik juga pada tekanan darah dan kesehatan tubuh.
\end{abstract}

Kata kunci: Antropometri atlet, BMI, BP

\section{ABSTRACT}

In order for sports to be occupied properly and without distraction, an athlete must be able to pay attention to the composition of fat in the body that is appropriate. The composition of fat in the body shows the degree of health of an athlete, can be seen through anthropometry. The purpose of this study was to determine the correlation between Body mass index/BMI and Blood pressure/ BP based on athlete anthropometric measurements in Buleleng Regency in 2019. Observational analytic research method with cross-sectional design. The research population is all the athletes of Buleleng Regency who are selected and prepared by the Indonesian National Sports Committee to take part in the National Championship. Accidental sampling is a sampling technique, obtained athletes as many as 121 people. Data collection methods with anthropometric measurements and athlete's blood pressure. Data analysis using analysis test (Pearson corellation test) at the 
significance level $(\alpha<0.05)$ using computerized system. The results of data analysis obtained $p$ value $=0.466(\alpha=0.000)$, showing a correlation between body mass index and blood pressure in athletes. Most athletes have the ideal BMI and normal BP categories. Based on this, each athlete must continue to control body mass and blood pressure, by always paying attention to proper eating patterns and schedules, balanced nutrition intake, regular physical exercise, and maintaining psychological health. Especially avoiding excessive anxiety so that BMI and BP remain in the range the ideal category so that it has a good effect on blood pressure and body health.

Keyword: an Atlet antropometri, BMI, BP

\section{PENDAHULUAN}

Setiap individu untuk meningkatkan derajat kesehatannya wajib melakukan pola hidup sehat, terlebih bagi seorang atlet. Atlet merupakan profesi yang menekuni bidang olahraga dan biasanya ikut serta dalam suatu event kejuaraan dalam pekan olahraga baik tingkat nasional maupun internasional. Atlet saat ini merupakan pionner dalam pertandingan olahraga dan dapat membawa nama baik negara untuk dikenal di Dunia internasional. Oleh karena itu seorang atlet harus memperhatikan kondisi fisik ketika bertanding. Atas dasar itulah perlu dilakukan suatu pengukuran atau tes kapasitas fisik atlet.

Pengukuran kapasitas fisik ini bertujuan agar para atlet pada berbagai cabang olahraga siap melakukan kejuaraan dalam bidang olahraga baik pada tingkat daerah, provinsi maupun pusat. Kesiapan yang dimaksud tidak hanya secara mental tetapi terlebih juga pada kondisi fisik atlet, sehingga dapat terhindar dari cidera maupun trauma dilapangan, serta dapat optimal melakukan aktivitas fisik pada cabang olahraga yang ditekuni. Kondisi kesehatan yang baik dengan bentuk tubuh ideal merupakan hal utama yang harus dimiliki oleh seorang atlet, bentuk tubuh yang ideal dapat diketahui dengan melakukan pengukuran antropometri tubuh untuk mendapatkan calon atlet yang unggul.

Atlet unggul harus mempunyai teknik dan fisik yang bagus serta bentuk tubuh yang menunjang dalam setiap cabang olahraganya. Para pakar olahraga sebelumnya telah banyak melakukan tes dan pengukuran fisik atlet, tetapi bila dilihat dari hasil yang dapat terpantau dalam suatu kejuaraan daerah nasional, ataupun internasional masih sedikit atlet hasil talent scouting (PPLP dan PPLM) berprestasi pada tingkat kejuaraan tersebut. Hal ini dapat disebabkan oleh kurang seriusnya pemantauan fisik atlet saat latihan terutama dari segi antropometri maupun pemeriksaan fisik lainnya, sehingga belum tercapainya hasil yang diharapkan. Di samping itu, adanya tuntutan target mengenai pemenuhan jumlah atlet yang mewakili suatu daerah, untuk mengikuti suatu kejuaraan akhirnya tidak menghiraukan kualitas maupun potensi atlet tersebut (Suhartoyo, 2015).

Untuk menghindari permasalahan tersebut, para atlet hendaknya dapat menjaga pola kesehatannya dengan baik, hidup teratur dan menghindari hal-hal yang dapat mengganggu kesehatannya. Pola hidup sehat adalah suatu gaya hidup dengan memperhatikan faktor-faktor tertentu yang mempengaruhi kesehatan, antara lain makanan dan olahraga yang teratur (Baskora et al., 2011). Berat badan merupakan hasil keseimbangan antara energi melalui penataan gizi dan pengeluaran energi aktivitas jasmani atau olahraga. Apabila asupan lebih besar dari pada pengeluaran maka berat badan akan bertambah, namun sebaliknya maka berat badan akan menurun. Berat badan harus di pertahankan tetap berada diseputar nilai ideal yaitu tidak kurang maupun lebih dari standar yang telah ditetapkan.

Body Mass Index (BMI) atau Indeks massa tubuh (IMT) adalah parameter yang digunakan untuk mengetahui status berat badan seseorang apakah tergolong normal maupun tidak (underweight, maupun overweight), data yang diperlukan untuk mencari BMI adalah data selisih antara berat badan dan tinggi badan. BMI juga dapat digunakan untuk menggambarkan komposisi tubuh secara kasar, meskipun tidak disertai dengan nilai dari konstribusi berat dari lemak dan otot (Supariasa, 2012).

Berdasarkan data Riskesdas tahun 2018 menunjukan angka 21,8 persen untuk penderita obesitas di Indonesia. Angka ini terus naik sejak Riskesdas tahun 2007 sebesar 10,5 persen dan 14,8 persen pada Riskesdas 2013. Selain itu prevalensi berat 
badan berlebih juga mengalami kenaikan tercatat tahun 2018 sebanyak 13,6 persen. Jumlah tersebut diambil dari hasil survei pada 300 ribu sampel rumah tangga di seluruh Indonesia yang dilakukan dalam Riskesdas. Indikator obesitas pada dewasa yaitu pada orang dengan indeks massa tubuh (IMT) di atas 27,0 dan overweight diatas 25,0. Di mana IMT normal berada pada angka 18,5 sampai 22,9 (Departemen Kesehatan RI, 2018).

Olahraga yang dilakukan oleh atlet bukan hanya sekedar aktivitas fisik yang bertujuan untuk membakar kalori dalam tubuh, tetapi lebih dari itu bahkan sangat menguras energi dalam tubuh. Intensitas olahraga itu penting diketahui terutama untuk seorang atlet. atlet harus mengikuti program olahraga yang ditekuni secara rutin dan teratur. Intensitas, kerutinan, serta teraturnya program olahraga yang dijalankan tersebut dapat berpengaruh terhadap nilai indeks massa tubuh. IMT tersebut dapat dikaitkan dengan resiko dari gangguan metabolisme darah yang ditandai dengan keadaan hipertensi maupun hipotensi.

Hipertensi merupakan suatu gangguan pada pembuluh darah yang mengakibatkan suplai oksigen dan nutrisi yang dibawa oleh darah, terhambat sampai ke jaringan tubuh yang membutuhkanya (Manuntung, 2018). Sedangkan hipotensi merupakan suatu keadaan di mana tekanan darah dalam arteri lebih rendah daripada batas ambang normal (Anggara \& Prayitno, 2013). Menurut JNC (Joint National Committee-VII), tekanan darah dapat dibagi menjadi tiga klasifikasi yakni normal, prehipertensi, hipertensi stage 1, dan hipertensi stage 2. (Pusat Data dan Informasi Kementerian Kesehatan RI, 2014).

Klasifikasi ini berdasarkan pada nilai ratarata dari dua atau lebih pengukuran tekanan darah yang baik, yang pemeriksaanya dilakukan pada posisi duduk maupun dalam keadaan istirahat. Hasil pengukuran tekanan darah terdiri dari nilai sistolik dan diastolik dalam satuan melimeter Hydrargyum $(\mathrm{mmHg})$. Tekanan darah normal berkisar antara 110120 mmhg (sistolik) dan 70-80 mmhg (diastolik) (Asfuah. S, 2012).

Menurut Badan Kesehatan Dunia WHO, terdapat satu milyar orang di dunia menderita hipertensi pada tahun 2011. Sedangkan di Indonesia jumlah orang dengan hipertensi telah mencapai persentase sekitar $25,8 \%$ dari total penduduk dewasa (Depkes RI, 2018).
World Health Organization (2013), menggambarkan sudah bahwa sebanyak $27,6 \%$ populasi dunia atau 985 juta orang menderita hipertensi, dengan perbandingan $50,64 \%$ pada pria dan $49,36 \%$ pada wanita. Dari jumlah tersebut, $65,85 \%$ diantaranya berada pada negara sedang berkembang.

Peningkatan berat badan memainkan peranan penting pada mekanisme timbulnya gangguan tekanan darah yaitu hipertensi pada orang dengan obesitas (Nurrahmani, 2012). Obesitas dapat mengakibatkan tekanan darah seseorang menjadi meningkat, karena orang yang memiliki berat badan diatas normal akan dapat meningkatkan kerja jantung dalam memompa darah keseluruh tubuh sehingga dapat meningkatkan tekanan darah. Hipertensi sering diartikan sebagai suatu keadaan dimana tekanan darah sistolik lebih dari 120 $\mathrm{mmHg}$ dan tekanan diastolik lebih dari 80 $\mathrm{mmHg}$. Tekanan darah sistolik adalah tekanan darah ketika jantung berdetak, sedangkan tekanan darah diastolik adalah tekanan darah ketika jantung beristirahat (Asfuah, 2012).

Penelitian oleh Aina (2013), didapatkan nilai korelasi antara indeks massa tubuh dengan tekanan darah diastolik adalah 0,246. Perolehan $p$ hitung $=0,04$, yang menunjukkan ada hubungan antara indeks massa tubuh dan tekanan darah diastolik. Penelitian berikutnya oleh Ramadhani (2013), menunjukan bahwa asupan lemak dengan tekanan darah sistolik memiliki nilai ( $p$ value $=0.000<0.05$ ) dan asupan lemak terhadap tekanan darah diastolik memiliki nilai ( $p$ value $=0.004<0.05$ ) serta menemukan hubungan antara BMI dengan tekanan darah sistolik ( $p$ value $=0.000$ $<0.05$ ) dan diastolik ( $p$ value $=0.002<0.05$ ), ini menunjukan adanya hubungan antara asupan lemak dan BMI terhadap tekanan darah.

Studi oleh Kartika et al. (2016), yaitu terdapat hubungan antara asupan lemak, aktivitas fisik dengan kejadian hipertensi didapatkan bahwa nilai $(p=0,009)$ untuk asupan lemak terhadap hipertensi namun tidak signifikan pada aktivitas fisik terhadap hipertensi. Perbedaan penelitian ini dengan penelitian sebelumnya yaitu penelitian ini mencari korelasi antara IMT dan tekanan darah pada seorang atlet, yang mana mereka dituntut harus memiliki kondisi tubuh/fisik yang baik dengan konsumsi makanan secara seimbang, agar memiliki berat yang ideal serta 
tekanan darah yang stabil untuk menghindari cidera saat berolahraga. Metode dari penelitian ini yaitu secara observasi langsung ke lapangan untuk tes fisik atlet, teknik pengumpulan sampel dan analisis data yang berbeda dari penelitian sebelumnya, serta menggunakan subyek yang berbeda. Jika penelitian sebelumnya tidak menggunakan atlet, yang mana atlet memang secara khusus diberikan pelatihan fisik dan pengaturan diet berbeda dari populasi umum. Atlet dipersiapkan untuk dapat memenangkan ajang kejuaraan, yang membutuhkan kondisi prima dan tubuh ideal yang merupakan syarat mutlak mengikuti perlombaan dimasing-masing cabang olahraga yang ditekuni.

Peningkatan berat badan memainkan peranan penting pada mekanisme timbulnya hipertensi pada orang dengan obesitas, sekitar 46\% dengan IMT 27 (katagori gemuk) adalah penderita hipertensi (Rohkuswara \& Syarif, 2017). Seseorang yang mempunyai kelebihan berat badan lebih dari $20 \%$ dan hiperkolesterol mempunyai risiko yang lebih besar terkena hipertensi (Putra, 2015). BMI juga merupakan alat yang sederhana untuk memantau status gizi orang dewasa khususnya yang berkaitan dengan kekurangan dan kelebihan berat badan. Penggunaan BMI hanya berlaku untuk orang dewasa berumur diatas 18 tahun (Supariasa, 2012).

The Framingham Heart Study menyatakan terdapat asosiasi erat antara obesitas dan hipertensi. Studi tersebut menyatakan bahwa $65 \%$ faktor risiko hipertensi pada perempuan dan $78 \%$ pada laki-laki berkaitan erat dengan obesitas. peningkatan $15 \%$ BB dapat menyebabkan peningkatan tekanan darah sistolik sebesar 18\%. Dibandingkan dengan individu yang memiliki BB normal/ ideal, seseorang yang memiliki berat badan overweight dengan kelebihan BB $20 \%$ mempunyai risiko delapan kali lipat menderita hipertensi (William \& Feeman, 2010).

Pada atlet tidak hanya tekanan darah tinggi yang harus dihindari tetapi juga tekanan darah rendah, karena dapat mengurangi energi dan stamina ketika bertanding sehingga asupan gizi para atlet harus dijaga dengan menu seimbang. Tujuan penelitian untuk mengetahui korelasional antara Body mass index/BMI dengan Blood pressure/BP berdasarkan ukuran antropometri atlet.

\section{METODE PENELITIAN}

Jenis penelitian yang digunakan adalah analitik observasional. Penelitian ini menggunakan pendekatan kuantitatif yaitu dengan menggunakan data-data yang diperoleh ketika melakukan tes pengukuran antropometri atlet. Penelitian ini dilakukan pada tanggal 30 Juli 2019 dan berlokasi di gelanggang olahraga (GOR) FOK Universitas Pendidikan Ganesha di Desa Jineng Dalem Kabupaten Buleleng. Populasi pada penelitian ini adalah seluruh atlet naungan KONI cabang Buleleng yang telah lolos seleksi untuk mengikuti kejuaran cabang olahraga (atletik, balap sepeda, basket, binaraga, bola voli, judo, karate, panjat tebing dan taekwondo) sebanyak 205 orang. Sampel penelitian didapat berdasarkan teknik accidental sampling yaitu sebanyak 121 orang atlet.

Teknik pengumpulan data dengan mengukur tekanan darah dan antropometri atlet untuk mengetahui berat badan dan tinggi badan yang diukur oleh peneliti bersama TIM GSC (Ganesha Sport Center) Undiksha dengan menggunakan instrumen seperti sphygmomanometer (air raksa), timbangan berat badan, dan pengukuran tinggi badan, serta lembar observasi berisi identitas atlet. Dinilai dengan mencari BMI melalui berat badan dan tinggi badan dengan katagori BMI: ideal $(18,5-24,9)$, tidak ideal $(>30,25-29,9$, $<18,5)$ serta blood pressure sistolik dan diastolik dengan katagori: Normal $(<120 /<80)$, tidak normal (120-139/80-89, $\geq 140 / \geq 90)$. Setelah melakukan pengukuran dan dimasukan kedalam lembar observasi, kemudian dilakukan pengolahan data sampai tabulasi, untuk melihat korelasi antara BMI dengan tekanan darah (blood pressure) atlet. Analisis data menggunakan analisis model linear yaitu analisis data menggunakan uji pearson corellation test pada taraf kemaknaan $(\alpha=0.05 \%)$, yang dianalisis melalui program dalam sistem komputerisasi.

\section{HASIL DAN PEMBAHASAN}

Karakteristik atlet berdasarakn ausia dan jenis kelamin dapat dilihat pada tabel 1 . Diketahui bahwa jumlah atlet yang terbanyak berusia dibawah 20 tahun yaitu 81 orang dengan persentase $(66,94 \%)$ dan berturutturut usia 20-30 tahun sebanyak 34 orang $(28,09 \%)$ dan usia lebih dari 30 tahun sebanyak 6 orang $(4,95 \%)$. Jumlah atlet yang 
memiliki jenis kelamin terbanyak yaitu laki-laki dengan jumlah 87 orang $(71,90 \%)$ dan jenis kelamin perempuan hanya sebanyak 34 orang (28,09\%). Pada Tabel 1 menunjukan rata-rata atlet berumur kurang dari 20 tahun yaitu sebanyak 81 orang atau sebagian besar yaitu $66,94 \%$ dan mayoritas memiliki jenis kelamin laki-laki. Usia di bawah 20 tahun merupakan usia remaja dan dewasa awal, pada usia ini resiko terjadinya tekanan darah tinggi ataupun hipertensi lebih rendah dibandingkan usia diatas 20 tahun, yang keadaannya berbanding terbalik. Insidensi hipertensi meningkat seiring dengan pertambahan usia (Manik, 2011).

Tabel 1. Distribusi Frekuensi Atlet berdasarakan Umur dan Jenis Kelamin

\begin{tabular}{lcc}
\hline \multicolumn{1}{l}{ Karakteristik Atlet } & $\mathbf{f}$ & $\%$ \\
Umur & & \\
$<20$ th & 81 & 66,9 \\
$20-30$ th & 34 & 28,1 \\
$>30$ th & 6 & 5,0 \\
Total & 121 & 100,0 \\
Jenis kelamin & & \\
Laki-laki & 87 & 71,9 \\
Perempuan & 34 & 28,1 \\
Total & 121 & 100,0 \\
\hline
\end{tabular}

Indeks massa tubuh seseorang dipengaruhi oleh usia dan jenis kelamin, wanita lebih mungkin memiliki persentase lemak tubuh yang lebih tinggi dibandingkan laki-laki dan usia yang tidak produktif lagi (Kristina et al., 2016), dengan kata lain bahwa laki-laki akan cenderung mempunya IMT yang ideal seperti pada hasil penelitian ini. Berat badan yang berlebih menyebabkan seseorang berisiko mengalami morbiditas dan mortilitas akibat gangguan kesehatan dan resiko penyakit yang dapat ditimbulkan oleh keadaan tersebut (Setyawati et al., 2017).

Berdasarkan Tabel 2, karakteristik Body Mass Index responden didapatkan bahwa katagori BMI ideal atau normal yaitu dengan jumlah 66 orang dengan persentase $(54,54 \%)$ dan jumlah BMl yang tidak ideal yaitu sebanyak 55 orang dengan persentase $(45,45 \%)$ dengan katagori overweight sebanyak 33 orang $(27,27 \%)$, obesitas sebanyak 13 orang $(10,74 \%)$ dan underweight sebanyak 13 orang $(10,74 \%)$. Hal tersebut menunjukan bahwa seorang atlet asupan nutrisi dan pola hidupnya telah diatur sedemikian rupa sehingga berat badan dan tinggi badannya seimbang dan dikatakan ideal.

\section{Tabel 2. Distribusi Frekuensi atlet berdasarakan BMI}

\begin{tabular}{lcc}
\hline \multicolumn{1}{c}{ Variabel } & $\mathbf{f}$ & $\%$ \\
BMI & & \\
Ideal $(18,5-24,9)$ & 66 & 54,54 \\
Tidak ideal & & \\
Overweight $(25-29,9)$ & 33 & 27,27 \\
Obesitas $(>30)$ & 9 & 7,43 \\
Underweight $(<18,5)$ & 13 & 10,74 \\
Total & 121 & 100 \\
\hline
\end{tabular}

Distirbusi frekuensi blood pressure atlet dapat dilihat pada tabel 3. didapatkan bahwa jumlah responden yang terbanyak adalah yang memiliki katagori tekanan darah (BP) normal (sistolik < $120 \mathrm{mmHg}$ dan diastolik < 80 $\mathrm{mmHg}$ ) yaitu sebanyak 79 orang atlet atau dengan persentase $65,28 \%$ dan responden yang memiliki tekanan darah dengan katagori prahipertensi yaitu sebanyak 35 orang $(28,92 \%)$ dan katagori hipertensi sebanyak 7 orang $(5,78 \%)$. ini menunjukan bahwa seorang atlet yang dapat menjaga asupan nutrisi sehingga kadar lemak dalam tubuh dapat seimbang, akhirnya akan berdampak pada metabolisme dalam darah dan tekanan darah menjadi teratur serta memiliki tekanan darah yang normal.

\section{Tabel 3. Distirbusi Frekuensi Atlet berdasarakan Blood Pressure}

\begin{tabular}{lcccc}
\hline Katagori Blood pressure & $\begin{array}{c}\text { Sistolik } \\
(\mathbf{m m H g})\end{array}$ & $\begin{array}{c}\text { Diastolik } \\
(\mathbf{m m H g})\end{array}$ & $\mathbf{f}$ & $\%$ \\
Normal & $<120$ & $<80$ & 79 & 65,3 \\
Tidak normal & $120-139$ & $80-89$ & 35 & 28,9 \\
Prahipertensi & $\geq 140$ & $\geq 90$ & 7 & 5,8 \\
Hipertensi & & & 121 & 100,0 \\
$\quad$ Total & & & & \\
\hline
\end{tabular}


Berdasarkan Tabel 4 korelasional BMI dan BP atlet, didapatkan bahwa jumlah responden yang terbanyak adalah responden yang memiliki katagori BMl ideal/normal dengan tekanan darah yang normal yaitu sebanyak 51 orang dengan persentase sebesar 64,55\%. Penderita prahipertensi terbanyak dialami oleh katagori BMI overweight yaitu sebanyak 16 orang $(45,71 \%)$, sedangkan pada keadaan hipertensi dialami juga oleh BMI katagori overweight dan obesitas yaitu masing-masing sebanyak 3 orang (42,85\%). Dari hasil analisis menggunakan korelasi pearson didapatkan nilai $P=0,466$ dengan taraf signifikansi 0,000 $(\alpha<0,05)$. Hal tersebut menunjukan bahwa ada korelasi yang signifikan antara body mass index/BMI dengan Blood pressure/BP.

Tabel 4. Hubungan BMI dengan Blood Pressure pada Atlet

\begin{tabular}{|c|c|c|c|c|c|c|c|c|c|c|}
\hline \multirow{3}{*}{ BMI } & \multicolumn{6}{|c|}{ Blood pressure } & \multirow{2}{*}{\multicolumn{2}{|c|}{ Total }} & \multirow{3}{*}{$\mathbf{P}$} & \multirow{3}{*}{ Sig } \\
\hline & \multicolumn{2}{|c|}{ Normal } & \multicolumn{2}{|c|}{ Prahipertensi } & \multicolumn{2}{|c|}{ Hipertensi } & & & & \\
\hline & $f$ & $\%$ & f & $\%$ & $\mathbf{f}$ & $\%$ & $f$ & $\%$ & & \\
\hline Underweight & 12 & 15,18 & 1 & 2,85 & 0 & 0 & 13 & 10,74 & & \\
\hline Ideal & 51 & 64,55 & 14 & 40 & 1 & 1,42 & 66 & 54,54 & & \\
\hline Overweight & 14 & 17,72 & 16 & 45,71 & 3 & 42,85 & 33 & 27,27 & 0,466 & 0,000 \\
\hline Obesitas & 2 & 2,53 & 4 & 11,42 & 3 & 42,85 & 9 & 7,43 & & \\
\hline Total & 79 & 100 & 35 & 100 & 7 & 100 & 121 & 100 & & \\
\hline
\end{tabular}

Massa tubuh yang seimbang akan berpengaruhi pada tekanan dalam pembuluh darah, karena semakin sedikit lemak dalam tubuh makanya aliran darah maupun metabolisme akan semakin lancar dibandingkan dengan seseorang yang memiliki lemak tubuh yang berlebih. Responden yang mengalami keadaan prahipertensi dan hipertensi yaitu mayoritas pada kelompok dengan katagori overweight serta obesitas. Hasil ini mendukung pernyataan oleh Dien et al. (2014) yang menyatakan bahwa faktor utama penyebab hipertensi yaitu kelebihan berat badan/ obesitas, semakin besar massa tubuh maka semakin banyak darah yang dibutuhkan untuk memasok oksigen dan makanan ke seluruh jaringan tubuh. Keadaan ini menyebabkan besarnya volume darah yang beredar melalui pembuluh darah akan meningkat, sehingga akan memberi tekanan yang lebih besar ke dinding arteri.

Hasil penelitian yang dilakukan oleh Sumayku (2014), yang menunjukkan bahwa indeks massa tubuh berlebih mempunyai hubungan dengan tekanan darah dengan nilai $p=0,001$ dan $0,004(p<0,01)$ dengan korelasi koefisien adalah 0,286 dan 0,252. Penelitian yang dilakukan oleh Daniati \& Erawati (2018), menemukan bahwa tekanan darah sistolik dan diastolik memiliki tingkat korelasi sedang dengan kadar kolesterol LDL (Low Density Lipoprotein) dengan nilai signifikansi masingmasing 0,00 dan 0,02. Begitu juga dengan hasil penelitian yang dilakukan oleh Utami et al. (2013) yaitu bahwa indeks massa tubuh berhubungan dengan tekanan darah sistolik dan tekanan darah diastolik.

Indeks massa tubuh yang berlebih dapat menimbulkan keadaan yang patologis oleh karena penyakit jantung dan pembuluh darah. Diabetes dan hipertensi juga merupakan akibat dari overweight dan obesitas yang sering terjadi pada dewasa dengan resiko yang akan meningkat seiring pertambahan usia (Suryati, 2015).

Pada usia remaja hingga dewasa awal seperti mayoritas responden dalam penelitian ini, menunjukan emosi yang dimiliki telah stabil dan pola hidup telah teratur, karena seorang atlet akan dididik untuk dapat mengendalikan diri serta emosionalnya dengan baik. Keadaan psikologis ini tidak kalah penting dengan keadaan fisik, seorang atlet telah dipersiapkan dengan mental dan fisik yang baik untuk menghadapi lawan-lawannya dalam suatu pertandingan cabang olahraga.

Penelitian oleh Purwanti et al. (2017), membuktikan bahwa adanya pengaruh indeks massa tubuh yaitu faktor psikologis seperti stres dikalangan mahasiswa, yang mana 
masalah psikis atau emosional ini sering dialami oleh remaja sampai usia dewasa awal. IMT dengan kategori kelebihan berat badan lebih banyak ditemukan pada laki-laki. Namun angka obesitas lebih tinggi ditemukan pada perempuan dibandingkan dengan laki-laki. Distribusi lemak tubuh juga berbeda antaralemak wanita dan pria, pria lebih sering menderita obesitas viscelar dibanding wanita (Asil, 2014).

Dari hasil penelitian ini menunjukan ada hubungan yang signifikan kuat antara body massa index dengan blood pressure pada atlet karena diperoleh niai $\alpha<0,05$ ( $p$ 0,000). Hasil penelitian ini mendukun penelitian yang dilakukan oleh Kartika et al., (2016), indeks massa tubuh berkorelasi langsung dengan kejadian hipertensi, resiko relatif untuk menderita hipertensi pada orang gemuk 5 kali lebih besar dibandingkan dengan orang yang memiliki berat badan normal seperti dalam penelitian ini yang mayoritas memiliki IMT yang ideal maka tekanan darahnya pun dalam keadaan normal, sedangkan yang mengalami overweight dan obesitas cenderung mengalami keadaan prahipertensi sampai hipertensi.

Dari hasil penelitian hampir setengahnya ditemukan juga BMI yang tidak ideal (overweight, obesitas dan underweight) yaitu dengan persentase sebesar 45,45 \%, dengan mayoritasnya mengalami BMI dengan katagori overweight. Ini menunjukan bahwa atlet juga dapat mengalami berat yang tidak ideal terutama berat berlebihan, hal ini dapat disebabkan karena usia yang tergolong remaja dibawah 20 tahun. Usia remaja cenderung mengalihkan emosi melalui makanan sehingga menyebabkan konsumsi makanan dengan kalori yang tidak seimbang dan pengaturan pola maupun jadwal makan yang salah.

Pada masa remaja seringkali mengalami ketegangan emosi yang meningkat akibat perubahan fisik dan kelenjar yang menyebabkan remaja sangat sensitif terhadap harapan-harapan baru, mudah mengalami gangguan, baik berupa gangguan pikiran, perasaan maupun gangguan perilaku. Konflik emosional, ketegangan dan kegelisahan yang terjadi pada remaja dapat memainkan peran dan perasaan tidak nyaman hingga menimbulkan kecemasan (Pinanti, 2012). Keadaan ini dapat berdampak pada tubuh yang berisiko mengalami obesitas.
Dari hasil penelitian ini ditemukan blood pressure yang tidak normal dengan katagori prahipertensi yaitu sebanyak $28,92 \%$ dan katagori hipertensi sebanyak 5,78\%. Hal ini dapat disebabkan karena adanya ketegangan dan kecemasan, oleh karena atlet ini dipersiapkan untuk mengikuti kejuaraan dan harus dikarantina. Jika hasil tes pengukuran fisik atlet baik maka atlet tersebut dapat mengikuti kejuaraaan, begitu pula sebaliknya. Kemungkinan hal ini menjadi penyebab dari kegelisahan atlet tersebut. Para atlet cemas, bahwa hasil tes bisa saja tidak meloloskan mereka untuk masuk mengikuti kejuaraan cabang olahraga yang ditekuninya.

Tingginya rasa cemas atau stres dapat menimbulkan peningkatan hormon kortisol dalam kelenjar adrenal dan mempengaruhi irama dan detak jantung menjadi tidak stabil dan cenderung meningkat. Menurut Andria (2013), stres sangat erat hubungannya dengan hipertensi. Stres merupakan masalah yang memicu terjadinya hipertensi di mana hubungan antara stres dengan hipertensi diduga melalui aktivitas saraf simpatis peningkatan saraf dapat menaikkan tekanan darah secara intermiten (tidak menentu). Stres yang berkepanjangan dapat mengakibatkan tekanan darah menetap tinggi.

Penyebab lain yaitu karena jenis kelamin, diketahui bahwa laki-laki lebih berisiko mengalami hipertensi, yang mana sesuai dalam penelitian ini yaitu atlet terbanyak berjenis kelamin laki-laki. Laki-laki memiliki peluang lebih besar untuk mengembangkan tekanan darah tinggi dari pada wanita. Jenis kelamin sangat erat kaitannya terhadap terjadinya hipertensi di mana pada laki-laki penyakit hipertensi lebih tinggi sering terjadi pada masa muda (Andria, 2013).

Dari hasil penelitian ini menunjukan penderita prahipertensi terbanyak dialami oleh katagori BMI overweight yaitu sebanyak $45,71 \%$, pada keadaan hipertensi dialami juga oleh BMI katagori overweight dan obesitas yaitu masing-masing sebanyak 42,85\%. Ini menunjukan bahwa ada kaitan antara kejadian tekanan darah yang tidak normal (prahipertensi dan hipertensi) terhadap BMI dengan katagori tidak ideal (overweight dan obesitas). Oleh karena itu berat badan yang berlebihan akan meningkatkan seseorang mengalami hipertensi. Makin tinggi lemak mengakibatkan kadar kolesterol dalam darah 
meningkat yang akan mengendap dan menjadi plak yang menempel pada dinding arteri, plak tersebut menyebabkan penyempitan arteri sehingga memaksa jantung bekerja lebih berat dan tekanan darah menjadi lebih tinggi. Tinggi lemak dapat menyebabkan obesitas yang dapat memicu timbulnya hipertensi (Andria, 2013).

Faktor-faktor penyebab timbulnya hipertensi antara lain faktor keturunan, ciri perseorangan dan kebiasaan hidup. Kebiasaan hidup seperti makan berlebihan dengan pola makan tinggi kalori, berlemak, mempunyai kebiasaan merokok dan minum alkohol merupakan hal yang dapat menimbulkan beberapa penyakit diantaranya seperti hipertensi. Pada orang dengan obesitas memiliki potensi untuk mengidap darah tinggi, karena pembuluh darah arteri ataupun vena kemungkinan besar dipenuhi oleh kandungan lemak, sehingga menyebabkan tekanan darah semakin meningkat (Situmorang, 2015).

Faktor yang dapat menyebabkan BMI tidak ideal serta tekanan darah yang tidak normal dari sampel yang diteliti, dapat disebabkan karena pemenuhan nutrisi yang tidak seimbang yang mana jumlah kalori yang dikonsumsi berlebihan dan pengaturan pola makan yang salah. Aktivitas fisik yang tidak teratur, keadaan psikologis seperti cemas maupun stres. Begitu pula dengan tekanan darah yang tidak normal dapat disebabkan oleh adanya kecemasan dan kegelisahan oleh karena stressor yang dirasakan atlet menjelang hari pertandingan. Oleh karena itu seorang atlet hendaknya harus tetap mengontrol pola nutrisi yang seimbang cukup kalori baik itu karbohidrat, protein, lemak dan vitamin serta mineral, latihan fisik yang rutin dan teratur serta menjaga kesehatan psikis dan emosional.

Atlet harus selalu dapat menjaga BMI dalam batas normal atau pada keadaan yang ideal. Peningkatan BMI selain berpengaruh pada kesehatannya, juga dapat berpengaruh pada pola aktivitasnya dan kegiatannya sebagai atlet pada cabang olahraga yang ditekuni. Sebagai atlet untuk dapat mencapai hasil kerja yang baik dalam pencapaian prestasi olahraga yang maksimal, yang berlaku pada seluruh cabang olahraga dengan tetap menjaga berat badan yang ideal, sehingga akan berdampak baik juga pada tekanan darah dan kesehatan tubuh secara keseluruhan.

\section{KESIMPULAN}

Persentase BMI atlet terbanyak pada katagori normal/ ideal sebanyak 54,5\%, Persentase Blood pressure terbanyak pada katagori normal yaitu sebanyak $65,3 \%$, Terdapat hubungan yang signifikan antara $B M I$ dengan blood pressure dengan taraf signifikansi $0,000(\alpha<0,05)$. Penulis juga dapat mengembangkan penelitian tersebut dengan menganalisis faktor-faktor lain yang berpengaruh terhadap kejadian overweight dan obesitas serta kenaikan tekanan darah pada atlet, sehingga dampaknya dapat dicegah. Keadaan tersebut diharapkan dapat teratasi melalui latihan fisik yang teratur dan selalu menjaga asupan nutrisi yang seimbang dengan pola konsumsi makanan yang tepat.

\section{REFERENSI}

Aina, S. (2013). Hubungan Indeks Massa Tubuh dengan Tekanan Darah Anak di Sekolah Dasar Negeri Medan. Jurnal Fakultas Kedokteran USU 1(1)

Andria, K. (2013). Hubungan antara perilaku olahraga, stress dan pola makan dengan tingkat hipertensi pada lanjut usia di posyandu lansia kelurahan gebang putih kecamatan sukolilo kota Surabaya. Jurnal Promkes, 1(2), 111-117.

Anggara, F., \& Prayitno, N. (2013). FaktorFaktor Yang Berhubungan Dengan Tekanan Darah Di Puskesmas Telaga Murni, Cikarang Barat Tahun 2012. Jurnal IImu Kesehatan, 5(1).

Asfuah. S. (2012). Buku Saku Klinik Untuk Keperawatan dan Kebidanan. Yogyakarta: Nuha Medika.

Asil, E. (2014). Factors That Affect Body Mass Index of Adults. Pakistan Journal of Nutrition, 13(5), 255-260.

Baskora, R., Sutardji, \& Woro, O. (2011). Sistem Informasi Perencanaan Pola Hidup Sehat melalui Keseimbangan Aktivitas dan Asupan Makanan. Jurnal Media IImu Keolahragaan Indonesia, 1(2), 181-194.

Daniati, \& Erawati. (2018). Hubungan Tekanan Darah Dengan Kadar Kolesterol Ldl (Low Density Lipoprotein) Pada Penderita Penyakit Jantung Koroner Di 
Rsup.Dr.m.Djamil Padang. Jurnal Kesehatan Perintis, 5(2).

Departemen Kesehatan RI. (2018). Riset Kesehatan Dasar (Riskesdas) Laporan Nasional 2017. Jakarta: Badan Penelitian dan Pengembangan Kesehatan, Depkes RI.

Dien, N., Mulyadi, \& Kundre, R. (2014). Hubungan Indeks Massa Tubuh (IMT) Dengan Tekanan Darah Pada Penderita Hipertensi Di Poliklinik Hipertensi Dan Nefrologi Blu RSUP Prof. Dr. r. d. Kandou Manado. Jurnal Keperawatan Univ Sam Ratulangi.

Kartika, L., Afifah, E., \& Suryani, I. (2016). Asupan lemak dan aktivitas fisik serta hubungannya dengan kejadian hipertensi pada pasien rawat jalan. Jurnal Gizi Dan Dietetik Indonesia, 4(3), 139-146.

Kristina, K., Pangaribuan, L., \& Bisara, D. (2016). Hubungan Index Massa Tubuh Dengan Hipertensi Pada Wanita Usia Subur (Analisis Data Riskesdas 2013). Jurnal Kesehatan Reproduksi, 6(2), 117127.

https://doi.org/10.22435/kespro.v6i2.4752. 117-127

Manik, E. (2011). Faktor-Faktor Yang Berhubungan Dengan Hipertensi Pada Lansia Di Posyandu Lansia Wilayah Kerja Puskesmas Parsoburan Kecamatan Siantar Marihat Pematangsiantar Tahun 2011. Skripsi. Fakultas Kesehatan Masyrakat. Universitas Sumatera Utara Medan.

Manuntung, A. (2018). Terapi perilaku kognitif pada pasien hipertensi. Malang: Wineka Media.

Pinanti, S. (2012). Hubungan Antara Tingkat Stress Dengan Siklus Menstruasi Pada Siswi Kelas 2 di SMA 1 Kendal. Jurnal Kedokteran Muhammadiyah Semarang, 1(2).

Purwanti, M., Putri, E., Ilmiawan, M., \& Rozalina, W. (2017). Hubungan Tingkat Stres Dengan Indeks Massa Tubuh Mahasiswa PSPD FK UNTAN. Jurnal Vokasi Kesehatan, 3(2), 47-56.

Pusat Data dan Informasi Kementerian Kesehatan RI. (2014). Infodatin Hipertensi. Jakarta: Kementrian Kesehatan Republik Indonesia.

Putra. R. (2015). The Effects Of Obesity In The Blood Pressure Elevation. Jurnal Majority,
4(3), 109-115.

Ramadhani, A. (2013). Hubungan kontrol tekanan darah dengan indeks massa tubuh pada pasien Hipertensi. Skripsi. Fakultas Kedokteran dan IImu Kesehatan Universitas Islam Negeri Syarif Hidayatullah Jakarta.

Rohkuswara, T. D., \& Syarif, S. (2017). Hubungan Obesitas dengan Kejadian Hipertensi Derajat 1 di Pos Pembinaan Terpadu Penyakit Tidak Menular (Posbindu PTM) Kantor Kesehatan Pelabuhan Bandung Tahun 2016. Jurnal Epidemiologi Kesehatan Indonesia, 1(2). https://doi.org/10.7454/epidkes.v1i2.1805.

Setyawati, B., Susilowati, A., Maisya, I. (2017). Usia dan indeks massa tubuh merupakan determinan tekanan darah diatas normal pada wanita usia subur. 40(2); 45-53.

Situmorang, P. (2015). faktor - faktor yang berhubungan dengan kejadian hipertensi pada penderita rawat inap di rumah sakit umum sari mutiara medan. Jurnal IImiah Keperawatan Imelda, 1(1), 145-152.

Suhartoyo. (2015). Komposisi Tubuh Dan Tipe Somatotipe Atlet Ukm Atletik Putra Universitas Negeri Yogyakarta Tahun 2015. Universitas Negeri Yogyakarta.

Sumayku, M. (2014). Hubungan Indeks Massa Tubuh dan Lingkar Pinggang dengan Tekanan Darah pada Mahasiswa Fakultas Kedokteran Universitas Sam Ratulangi. Retrieved December 15, 2019, from http://ejournal.unsrat.ac.id/index.p hp/eclinic/article/viewFile/5022/45 40

Supariasa, N. (2012). Penilaian Status Gizi. Jakarta: EGC.

Suryati, A. (2015). Faktor-faktor yang berhubungan dengan terjadinya hipertensi essensial. Jurnal Kedokteran Dan Kesehatan, 2(1), 183-193.

Utami, D., Kusuma, I., \& Achmad, A. (2013). Hubungan Kebugaran Jasmani Dan IMT Dengan Tekanan Darah Pasien Diabetes Melitus Tipe 2. Jurnal Acta Pharmaciae Indonesia, 1(1), 43-49.

William, E., \& Feeman, J. (2010). BGS Graph Predicts Better Than the Framingham Risk Score. Journal of Clinical Lipidology, 4(3), 203-212.

World Health Organization. (2013). Childhood Overweight and Obesity. Global Strategy on Diet, Physical Activity and Health, WHO. 